\title{
A Design Thinking Approach to Increasing Student Efficacy in the Internship Search Process
}

\section{Dr. Katherine McConnell, University of Colorado Boulder}

Katherine McConnell is a Senior Professional Development Advisor in the Department of Mechanical Engineering at the University of Colorado Boulder. Her work focuses on the integration of experiential learning, industry connections, and career-oriented education across the curriculum. 


\title{
A Design Thinking Approach to Increasing Student Efficacy in the Internship Search Process
}

\begin{abstract}
This research paper presents the findings from a study out of the University of Colorado Boulder focused on using design thinking to improve internship search related resources and supports. The goals of the study were to 1) identify points of disconnect that students experience during the internship search process and 2) work collaboratively with student participants to identify useful, creative solutions. The identified points of disconnect can be viewed as potential points of attrition, where students have the highest likelihood of dropping out of the internship search process. By thinking strategically and creatively about how to address them, those points of attrition can be converted into leverage points for positive change.
\end{abstract}

Design thinking is a framework that will be familiar to many engineering educators for its use in product design. As a research and program improvement methodology, design thinking has the benefit of valuing students as co-innovators in the change process. It consists of a non-linear five stage process that includes building empathy, defining the problem, ideating solutions, prototyping, and testing. The design thinking process used in this study was supported by both quantitative and qualitative methods with a total sample size of 679 student participants. Quantitative data is presented from the department's senior survey $(n=654)$. Qualitative data is presented from 12 interviews and 3 focus groups $(\mathrm{n}=25)$ conducted during Spring 2019.

The four identified areas of disconnect that form the basis for this paper include: 1) sustained motivation, 2) finding the right options, 3) understanding the process, and 4) standing out. For each theme, information is presented that relates to the first three stages of the design thinking process. The empathy stage is addressed through a discussion of specific issues shared by interview and focus group participants, with appropriate connections to educational and cognitive theory. The issues are then distilled into a succinct problem statement. Each section ends with a list of potential ways to address the problem statement, with proposed action steps drawn from the ideation phase of the study. In the conclusion of the paper, plans are shared related to future prototyping, testing, and ongoing ideation of programmatic changes and improvements.

\section{Introduction}

Internships have been shown to be of great value for both student learning and career attainment. They allow students to build the real-world skills and perspective necessary to engage effectively with their own education [1]. There is also evidence to show that they contribute to greater career engagement later in life [2] and that having an internship is one of the top qualifications that employers look for in new graduates [3]. At the University of Colorado Boulder specifically, 87\% of AY 15-18 Mechanical Engineering graduates who completed an internship rated their experience as "extremely useful," "very useful," or "useful" [4]. Despite those clear benefits, only $44 \%$ of the department's graduating students for the same time period reported having completed an internship prior to graduation [4]. 
An initial focus group with members of the Mechanical Engineering Student Advisory Board was held in Spring 2018. The original goal of that conversation was to discuss strategies for motivating students to see the value in an internship and start searching for positions. The primary outcome was a shift in that goal. The students who participated reported that they understood the value of an internship and were motivated to look for one, but felt frustrated and demoralized by the process. There was a strong perception that the internship search process was largely dependent on a combination of luck and connections, which made it challenging to stay motivated through what is often a grueling process. That perception was supported by data from the department's Senior Survey, with 44\% of ME students graduating in AY 15-18 who completed an internship reporting that they found the position through personal connections [4]. It was also supported by responses to a survey administered during Fall 2018 as part of the department's sophomore seminar, with a mean response on both the pre and post-test of 4.6/5.0 $(n=180)$ for the question "To what extent do you believe that an internship is a valuable part of your undergraduate education?" [5].

This study digs deeper into those initial findings to identify resources and supports that could be implemented to better empower students in Mechanical Engineering through all phases of the internship search process. The methodology focuses on stepping away from preconceptions to learn about students' experiences navigating the internship search process and work collaboratively with them to identify productive solutions to the challenges they encountered. Findings from the study will continue to be refined through an iterative implementation process. Overarching research questions guiding the study include:

1. What are the points of disconnect that lead students in the department of study to either opt out or be unsuccessful in an internship search process?

2. How can the department productively and creatively address those areas of disconnect in a way that goes beyond traditional career coaching?

\section{Study Context}

The context for this study is the Department of Mechanical Engineering at the University of Colorado Boulder. As of the Fall 2018 census date, there were 979 undergraduate students rostered in the department. Of those students, $19.4 \%$ identified as female, $15.3 \%$ as first generation, $11.5 \%$ as international, and $15.7 \%$ as a member of a race or ethnicity that is underrepresented in STEM fields [6, 7].

Undergraduate degree requirements in the department include both a sophomore seminar and a co-curricular Design Your Career requirement focused on various aspects of career and professional development. Because the department has its own career development framework that is designed to support a specific and relatively small population of students, there is great flexibility to tailor program requirements, supports, and resources to fit the needs of that student population. This study seeks to inform changes and improvements to that framework. While certain aspects of the findings are likely to resonate with professionals at other universities, they are not intended to be generalizable beyond the department of study. 


\section{Methods}

The methods for this study followed a design thinking framework. That approach was selected because of its emphasis on developing empathy with the end users and then moving forward using that empathy as a foundation for rapidly ideating a wide range of possible solutions. It was also selected because of its emphasis on creativity and group problem solving, which was an ideal fit for a research problem focused on providing better resources for a group of highly involved, capable students with a lot of thoughts and ideas to contribute. The specific design thinking model used in the study was the nonlinear, five-step process popularized by Stanford's d.school. An image showing the design thinking process is included below in Figure 1 [7].

Figure 1: Stanford d.school Design Thinking Model

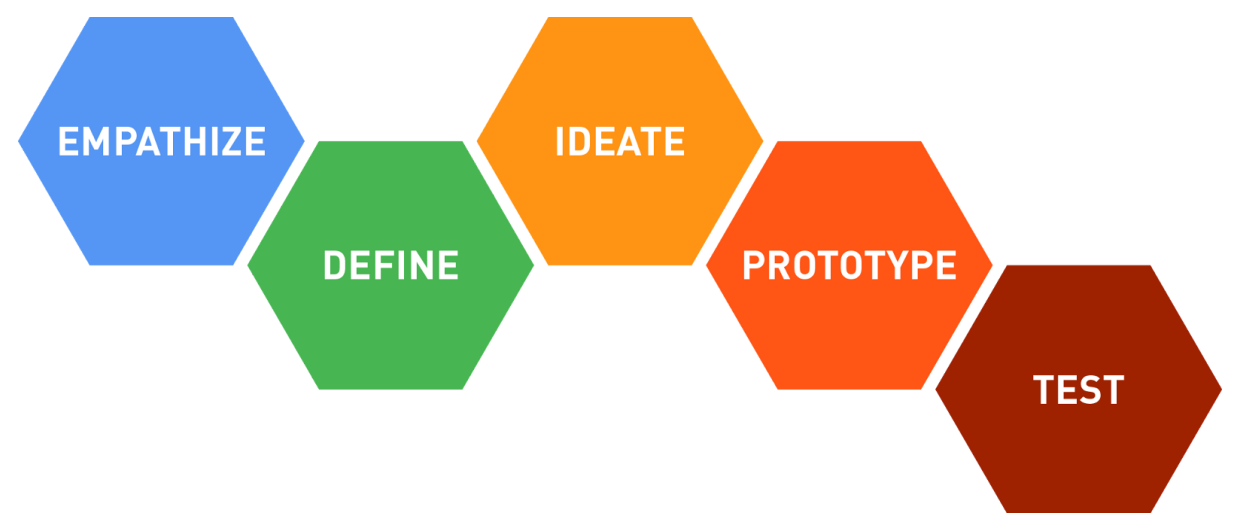

This paper encompasses the first three stages in the design thinking process, stopping just short of the prototyping phase. The prototype and test phases of the project are ongoing, but are largely outside the scope of what could reasonably be contained in this publication. Because the design thinking process is non-linear, the prototype and test phases will continue to require a revisiting of earlier findings and additional exploration related to the empathize, define, and ideate phases.

\section{Inspiration \& Foundational Data Collection}

As was noted in the introduction, an initial focus group was conducted with the Mechanical Engineering Student Advisory Board during Spring 2018. An additional focus group was conducted with the department's industry partners later in Spring 2018. Those conversations formed the foundation for this study and were followed by a period of collecting and analyzing existing data sources. Survey data, previous strategic planning documents, and resource websites were reviewed in order to gain a baseline understanding of current resources and outcomes related to the internship search process. A specific data source of note was the Senior Survey administered by the College of Engineering and Applied Science. The Senior Survey is a graduation requirement for students in Mechanical Engineering and asks a number of questions related to internship attainment, search strategies, companies of employment, location, satisfaction, and perceived benefit. Because the survey is a graduation requirement, there was a $100 \%$ response rate for AY 15-18 BS graduates with a total sample size of 654 [4]. 


\section{Primary Data Collection}

The primary qualitative component of the study was conducted during AY 18-19. That component was designed to address the empathy and ideation stages in the design thinking process. Because the primary researcher is responsible for implementing professional development activities in the department of study, it was important to both collect student perspectives on the current offerings and closely examine the student experience with regards to event participation and use of provided resources. Related empathy-building exercises included actively networking at a university-wide career fair, using the university-provided jobs database to search for positions, and attending a variety of career-related events. The goal of those exercises was to view the activities from a fresh perspective, by stepping away from the back-end logistical components and experiencing them from as close to a "beginner's mindset" [8] as possible.

While the methods described above provided some context for the study, the main data collection method was a series of interviews and focus groups designed to gather input directly from students engaged in the internship search process. An initial focus group was conducted with a team of student leaders involved with initiatives focused on career development and industry engagement within the department. That initial focus group included 8 participants and focused on identifying stumbling blocks, demotivators, and points of disconnect in the internship search process. Because of their role as student leaders, the participants served as both experts and end-users within the design thinking framework. The focus group was split across two days and included a variety of brainstorming techniques including think-pair-share, a post-it board, and large group discussion. In contrast to later focus groups and interviews that were led by the primary researcher, the initial focus group was led by a faculty partner in order to free up the primary researcher to observe and take notes. The outcome of the focus group was a substantial list of issues related to the internship search process and a corresponding list of potential ideas for beginning to address those issues.

Following the initial focus group, a test interview was conducted with a student who had previously expressed an interest in providing input. That interview was used both to collect data and to test potential interview questions. After completing that initial interview and finalizing the interview protocol, a call was sent out for interview participants from the larger department. A total of 16 additional volunteers participated in either an interview or focus group, for a total of 25 participants ( 19 male, 6 female) in the qualitative phase of the study. Participants varied broadly in terms of their class year, career interests, and where they were in the internship search process. All volunteers who expressed an interest were welcome to participate, with no selection based on demographics.

The interviews and focus groups were semi-structured, with enough flexibility to follow the students' interests in different directions. That method is consistent with the "empathize" phase of the design thinking model, which emphasizes the importance of being open to new insights and allowing the interview to flow into a conversation. Questions included in the interview protocol focused on a combination of the students' overall experiences in the department, their experiences with the internship search process, the stumbling blocks they encountered during 
that process, and their thoughts on what they would like to see in terms of changes. Each interview concluded with a "dream big" question that asked students to imagine how they would answer a question about internship supports if there were no constraints (i.e.: financial support, staffing, existing structures). Some initial attempts were made to gather feedback during the interviews related to ideas that had already been proposed, but that strategy was abandoned in favor of one that more clearly separated the test phase from the initial interviews. Focus groups were left even more open ended, with the conversation largely guided by the students' interests and observations.

\section{Data Analysis}

An adapted version of the "saturate and group" strategy from the Stanford d.school was used to organize the collected data and identify themes [7]. That strategy is very similar to the coding process commonly used in qualitative research, but differs in its emphasis on tactile and visual data processing. The strategy used for this study was more visual than a traditional coding process, but less tactile than "saturate and group."

The first step in the data analysis process was to transcribe all of the notes from the interviews, focus groups, and observations into a single document. The notes were reviewed to identify key points of interest, which were defined as points that were either reiterated by multiple participants or that presented a unique perspective or approach to the subject. Notes that did not fall into either of those categories were moved to a separate document. The remaining notes were printed and reviewed in paper form, to allow for a greater visual field of reference in reviewing the data as a whole. That process was roughly equivalent to the "saturate" phase from the d.school's process, with computer printouts substituting for post-it notes. The identification of emergent themes was an iterative process with multiple rounds of highlighting, hand-written notes, and sorting between documents.

After a number of iterations, six themes were identified that encompassed the most salient observations from the interview process. Those themes were entered as headers into a spreadsheet, with the related notes from the data collection phase of the study sorted below each header. An important component of that step included noting points of overlap between themes, which would be useful later on in mapping points of intersection between future programmatic efforts. After the sorting process, the data was condensed a final time to arrive at a set of four themes that each corresponded with an area of disconnect that students experienced and/or observed related to the internship search process: 1) sustained motivation, 2) finding the right options, 3) understanding the process, and 4) standing out.

Once those themes were identified, the information from the spreadsheet was pulled into two lists. The first list focused on feelings and experiences that corresponded with each theme. Those feelings and experiences were used to define a series of problem statements [9] in order to better understand and communicate the issues that came up for students during the internship search process. The second list focused on potential action items that corresponded with each theme. That list included both ideas directly proposed by students during focus groups and interviews, as well as additional ideas developed through ongoing conversations with department 
stakeholders throughout the course of the study. The action items were compiled into a master list, then sorted by theme through a process of matching issues with potential solutions.

\section{Foundational Data}

This section details findings from the Senior Surveys conducted by the College of Engineering and Applied Science during AY 15-16, 16-17, and 17-18. The total sample size for all three years was 654 students [6]. Basic employment information was calculated for graduates during each year included in the data set. That data is shown below in Figure 2. The numbers presented include both paid and unpaid positions. While the vast majority of the positions were paid, unpaid research positions $(16 \%)$ were much more common than unpaid internships $(2 \%)$.

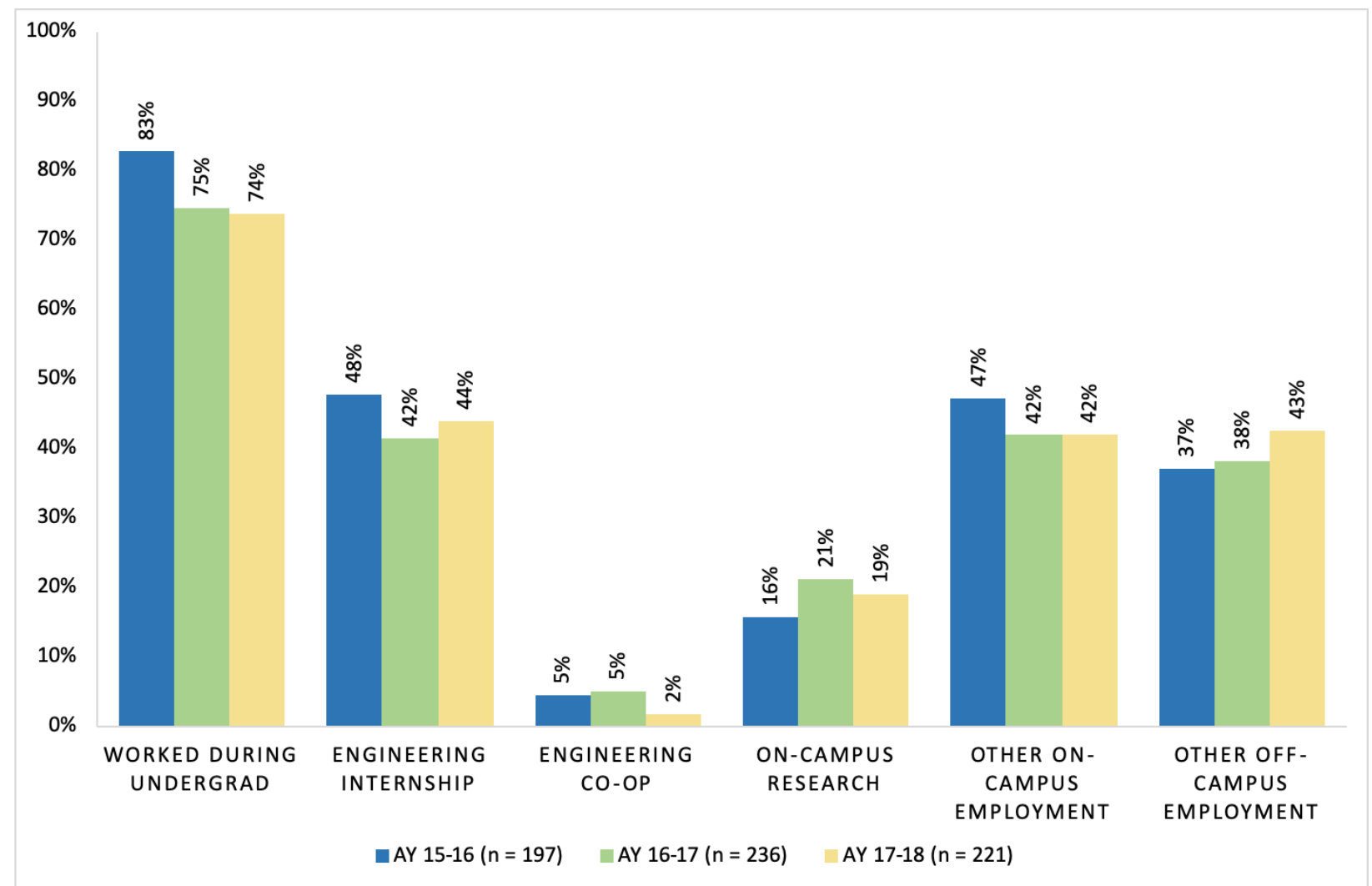

Figure 2: Percentage of BS Graduates Reporting Work Experience

Aggregate data across the full three year sample was also analyzed to determine how students found their first internship position, as well as how satisfied they were with that position and how useful they found it. Satisfaction and usefulness ratings are shown below in Figures 3 and 4. The data clearly shows high rates of both satisfaction and usefulness, with $87 \%$ of graduates rating their first internship as "extremely useful", "very useful", or "useful" and 83\% reporting that they were "very satisfied" or "satisfied" with their first internship position. 


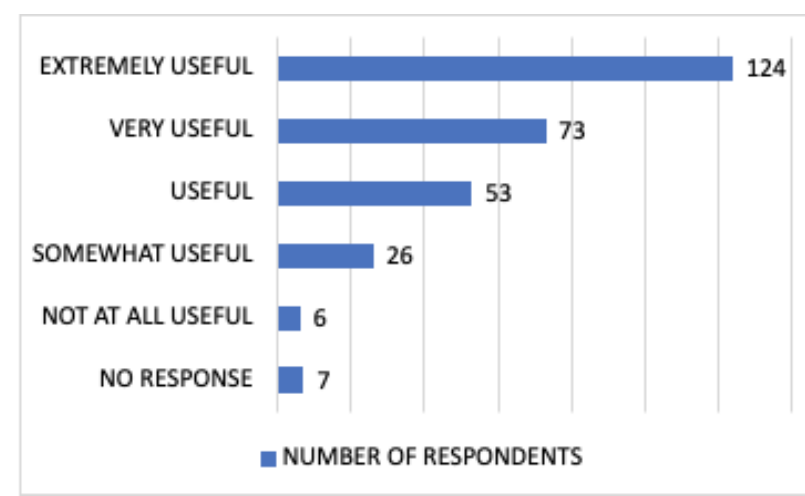

Figure 3: To what extent did you find your internship position useful in reaching your educational goals?

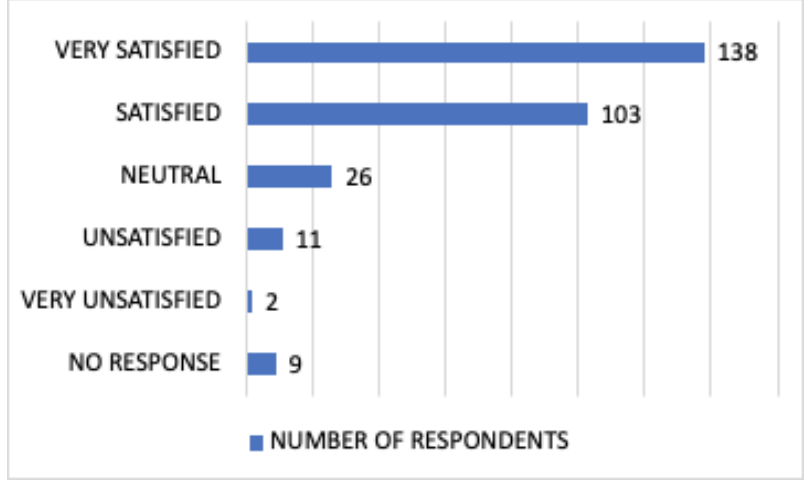

Figure 4: To what extent were you satisfied with your internship position?

Statistics related to how students found their first internship position are shown below in Figure 5. While the categories included in the Senior Survey did not align perfectly with the internship search methods discussed as part of this study, they do show a clear trend of students finding positions through networking and through taking the initiative to seek out resources beyond what was provided by the university. Neither "other networking" or "took the initiative to contact companies of interest" were included in the available options.
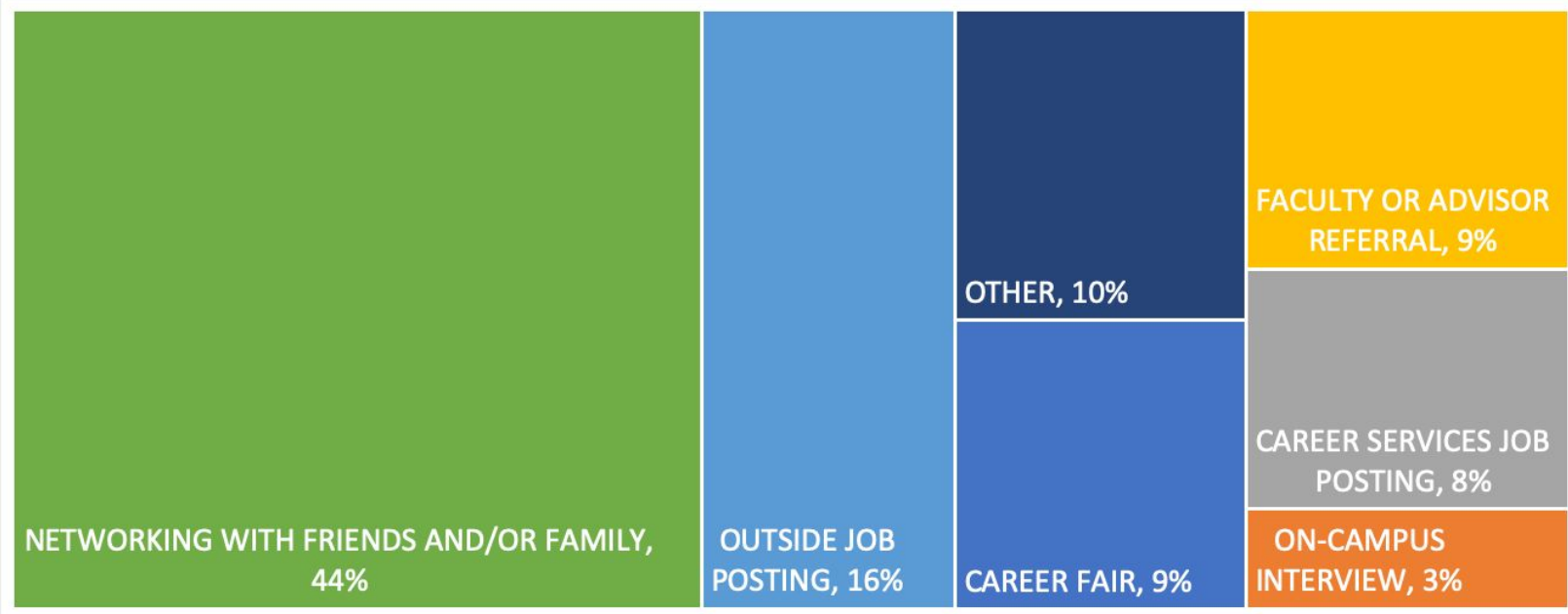

Figure 5: How did you find your first internship position?

\section{Study Findings}

Findings from the empathize, define, and ideate phases of the study are detailed below. They are grouped by theme with each theme representing a point of disconnect in the internship search process. The themes are organized in rough chronological order to show how they come into play as students move through the process of searching for an internship. 


\section{Theme 1: Sustained Motivation}

While initial motivation was mentioned occasionally throughout the data collection process, it was far outshadowed by the more significant issue of sustained motivation. Many of the student participants noted that while they were initially excited to look for internships, they quickly discovered that it could be a long and exhausting process. They saw friends getting offers and felt like maybe they weren't good enough somehow, or just weren't lucky enough to have the right connections. Those feelings led to the widespread perception that putting in time and effort isn't enough to get an internship. Participants also noted a tendency to prioritize the reliable short-term rewards associated with studying and doing homework, rather than the possible long-term reward that could come from searching for and applying for internships. That prioritization is consistent with the values communicated in other aspects of the college experience, with pressure to prioritize school above other activities.

Issues related to sustained motivation are exacerbated by the structure of the internship search, which often involves consistent rejection or lack of feedback followed by a single job offer after months of effort. That experience contrasts with what is known about the factors that motivate students to continue working productively towards their goals. Consistent, constructive feedback has repeatedly been shown to increase student learning and achievement. A lack of feedback or feedback that isn't structured in a constructive way can have the opposite effect [10]. An internship search is also often students' first foray into the world of professional job searching. While they may have excellent self-efficacy in other areas of their lives, a lack of mastery experiences and positive feedback related to the internship search can lead students to interpret initial rejection as a sign that they will never succeed or that the search process isn't a good use of their time [11]. As one focus group participant said, there needs to be a "shift from rejection equals never to rejection equals try again."

A related issue was that the internship search, in contrast to the college application process, does not have a standard timeline or due dates. Students reported feeling pressure to constantly be looking for postings and opportunities. With many jobs only being posted for a few days or a week, checking out of the process to focus on midterms or other priorities could lead to a missed opportunity. Students also tended to primarily report having a reactive job search, with applications submitted when jobs posted. That is in contrast to a proactive job search, with identification of target companies coming before jobs are posted. That pressure to constantly be looking for positions can lead to search fatigue, without the accompanying sense of accomplishment that comes from tangible progress towards a goal.

Those observations can be summarized with the problem statement: Students need to be able to stay motivated throughout the internship search process, despite rejection and a lack of short-term positive motivators. Assuming that it is not possible to require that employers provide constructive feedback to all of their applicants, a potential strategy for addressing that issue is through a combination of tailored messaging and concrete tools. A sampling of related ideas from the ideate phase of the study is included below:

- Use statistics and storytelling to normalize that job searching is hard and takes time. Specific suggestions included visual displays of alumni stories, a panel featuring 
participants who've completed internships, and statistics showing the average number of applications students submitted prior to getting their first internship offer.

- Develop a structure for students to project manage their own job search. A project management approach to the job search would both emphasize that the internship search process is complex enough to require project management and provide students with tools for managing the search process over an extended period of time.

- Make sure students know that there are support resources available for them. Even if they don't get feedback from employers, there are peer advisors, faculty, staff, and alumni who are happy to work with them to provide input and support throughout their search.

\section{Theme 2: Finding the Right Options}

Many students reported that they chose Mechanical Engineering because of the breadth of opportunities that it presented, then struggled to identify the opportunities that would be most relevant or most interesting to them. That issue was compounded by both the hidden job market (i.e.: small companies often don't post and promote positions in the same way large companies do) and the lack of specificity in job postings, with second and third-year engineering students often not having the base of knowledge yet to distinguish between positions based on industry-specific terms. It was also compounded by perceptions of certain fields or positions as more or less desirable, without a clear understanding of the full industry landscape or how broad categories like "design" map across fields and roles.

There was an interesting observed phenomenon of students feeling overwhelmed by the volume of options available to them while also feeling like it wasn't possible to find roles that would be a good fit for them. At face value those seem to be contradictory issues, but the problem started to come together after participating in a career fair and performing user testing of the university's jobs database. It was easy to quickly find hundreds or even thousands of positions with the search term "mechanical engineering intern", but much harder to identify positions within those thousands of options that would be a good fit. When asked how they selected jobs to apply for, there was a trend of students indicating that they tended to give the most consideration to positions at companies whose names they recognized. That emphasis on brand recognition was especially apparent in situations where the students were asked to navigate a long list of employers or job postings, as is the case with both online job boards and on-campus career fairs.

While having many career options is an important advantage of pursuing an engineering degree, there is also evidence to show that having too many choices can be demotivating rather than empowering [12]. Iyengar and Lepper documented a series of three studies designed to test the impact of many vs. few choices on students' and consumers' decision making process. They found that "participants in the extensive-choice condition reported experiencing the decision-making process as being simultaneously more enjoyable, more difficult, and more frustrating" [13, p. 1003]. Students given more options for extra credit assignments were less likely to follow through on completing the assignment and consumers given more options for free samples were less likely to purchase the product they had sampled. While the paper focused on low-impact study settings (i.e.: selecting a chocolate, writing an essay), the authors hypothesized that the effect of the observed "choice overload" would be even more pronounced 
in situations where an informed decision required "substantial time and effort" [13, p. 1004]. That phenomenon has direct parallels to the internship search process. It helps to explain how students can be simultaneously overwhelmed by the immense volume of potential options available to them and frustrated by the lack of perceived good options from within that pool.

The observations above can be summarized with the problem statement: Students need effective strategies for identifying and understanding the internship options available to them. While that is a significant problem to address, it's also one that fits well within the educational mission of a university setting. It requires content development/delivery and a plan for helping students acquire a new skill, which are areas that will be familiar territory for most educators. Related ideas from the ideate phase of the study include:

- Increase communication about career paths of ME alumni. Include representation of non-linear career paths to decrease pressure to find the perfect fit in a first internship.

- Develop industry maps that show how positions connect within different subfields. For example, how careers in areas like energy distribution and analysis connect with the goal of working towards more sustainable and efficient energy systems.

- Compile a list of companies that have historically hired ME students and a list of keywords other than "mechanical engineering intern" that can be used to search for relevant positions.

- Provide opportunities for smaller, local companies to showcase projects/tech and get students excited about working with them. That could be an event, a physical display within the department, or a website tailored for student use.

- Design a tracking and decision making tool that can be used to help students identify companies they'd be interested in and track if/when they should follow-up with each one to find out about internship opportunities.

\section{Theme 3: Understanding the Process}

A recurrent theme throughout the interview process was that the internship search reality that students encountered was different than the one that they were prepared for by advisors from within the university. They had benefited in the past from their ability to follow directions, but found that the best way to find an internship was to work outside of the formal system of resumes, cover letters, and online applications. They also found that the kinds of behaviors that were rewarded within the internship search process were not things that would be rewarded or even considered socially acceptable outside of that setting. For example, continuing to apply to the same company after being told no repeatedly or attempting to skip the line by reaching out directly to someone at the company rather than following the instructions to apply online.

A related theme expressed during the interview process was a feeling of career fairs and other structured recruiting events being "the wrong kind of connection." There was a strong perception that those events encouraged an artificial approach to relationship building, which students didn't see as beneficial for either them or the employer. Students who had completed more internships tended to report a shift in how they viewed on-campus recruiting events, from a strict reliance on elevator pitches towards a more comfortable approach based on information sharing and genuine interest in the company. Students less experienced in the job search process 
reported the opposite, with choices related to apparel and etiquette forming a barrier to participation. Students also reported being overwhelmed by the number of options for networking and recruiting events, without clear guidance as to which events would be most useful for them.

The observation that there was a disconnect between the university's recommended strategies for finding an internship and how students were actually finding positions was apparent in the Senior Survey data presented earlier in this paper. When asked how they found their first internship, only $24 \%$ of students reported that they found the position through either a university $(8 \%)$ or outside job posting (16\%). The same data set showed that only $20 \%$ of students found their first internship through formal campus resources, including the university job board (8\%), career fairs $(9 \%)$, and on-campus interviews (3\%). That is in contrast to the $44 \%$ who found their first internship by networking with friends and family. Many of the most common strategies noted by study participants (i.e.: networking events other than career fairs, reaching out to companies of interest, etc.) were not even included as response options [4].

Challenges related to understanding how the internship search works can be summed up with the problem statement: Students and advisors need to adjust their methods for internship searching based on what is known about how students obtain positions. Ideas for changes related to that problem statement include:

- Transition away from a view that applying online is how you get the job. Work to build a strong alumni community, so that networking becomes part of the student experience instead of something that happens once a semester at the career fair.

- Host an "Ask Me Anything" panel with hiring managers to talk about how candidates can stand out in a hiring process, including how they can make the best use of networking and on-campus recruiting events.

- Coordinate a mock career fair with past interns that provides students with an opportunity to practice recruiting and networking interactions in a low-pressure environment. Provide feedback on what students did well and what they could improve on, to help them be more confident participating in future events.

- Directly state implied etiquette related to networking and recruiting events. Tell students what the dress code is for each event, if it's okay to ask alumni for their contact information, if it's okay to bring resumes, etc.

\section{Theme 4: Standing Out}

A final theme from the interviews and focus groups was that for students who succeeded at overcoming each of the three challenges already described, there was still a hurdle associated with standing out in a pile of very similar applications. Students expressed concerns about their ability to clearly explain why they would be a uniquely strong candidate when the other 200+ students in their graduating class all had similar experience. They also expressed concerns about the limitations of a resume and cover letter when it came to demonstrating qualities like teamwork skills, work ethic, and problem solving. 
In some ways those concerns link back to self-efficacy [11], but they also get at the reality of the job search process. With internship postings at top companies regularly yielding over a hundred applications per opening, figuring out how to stand out in a positive way is a real concern. The emphasis on networking covered in the previous section is one of the most effective ways to stand out, but there are also steps that students can take to make themselves more competitive candidates. Pushing students to develop those out-of-class skills requires a shift from a traditional view that places academics first, to a more holistic view that emphasizes students' ability to proactively shape their own college experience.

A problem statement to summarize that issue is: Students need to be empowered to seek out learning and skill development opportunities outside the prescribed curriculum. A related problem statement focused on the marketing aspect of the job search is: Students need to be able to effectively self-promote throughout the internship search process. Recommendations from the ideation phase of the study related to both skill development and self-promotion include:

- Encourage students to start exploring career fields early, so that they can see what skills are valued and identify strategies for gaining those skills. Work towards a culture where skills gained independently are valued as much as skills gained in the classroom.

- Provide better resources for selecting technical electives that will help students work towards their career goals. Increase the availability of skill building workshops and professional certifications, including promoting existing opportunities offered through other departments and professional organizations.

- Publicize engineering competitions and other short-term opportunities for students to gain concrete experience. Provide logistical support for students interested in participating in those opportunities to help them form project teams.

- Encourage companies to consider non-traditional recruiting strategies that allow them to interact with students in a project-based or problem-solving setting that goes beyond traditional application materials.

\section{Conclusion \& Next Steps}

Findings from this study were applied to the development of a strategic plan for student professional development, which was presented to department leadership in Fall 2019. That plan includes both needs assessment data from the study and a mapping of key recommendations to department and college level strategic goals. That mapping will serve as a resource for both soliciting support for new program components and structuring assessment activities in a way that aligns with larger strategic goals.

The next step in the design process will be to identify ideas from within the long list of proposed changes that can be implemented quickly and easily, as well as ideas that require a more substantial input of time and/or resources but that should be a priority moving forward. Throughout the implementation process, there will be an ongoing focus on prototyping, testing, and continuing to involve students in the design process as both consultants and active drivers of cultural and programmatic change. 


\section{Acknowledgment}

Thank you to Brent Wilson of the University of Colorado Denver and Julie Steinbrenner of the University of Colorado Boulder for their support and encouragement throughout this project. Thank you also to the students who participated in interviews and focus groups including members of the Mechanical Engineering Student Advisory Board, the University of Colorado Boulder Chapter of ASME, and the ME Student Apprentices.

\section{References}

[1] E. Jones, "Transforming the Curriculum: Preparing Students for a Changing World", ASHE-ERIC Higher Education Report, San Francisco, CA, 2002. [Online]. Available: files.eric.ed.gov/fulltext/ED470041.pdf.

[2] "The 2014 Gallup-Purdue Index Report", Gallup, Washington, DC, 2014. [Online]. Available: www.luminafoundation.org/files/resources/galluppurdueindex-report-2014.pdf.

[3] N. Saltikoff, "The Positive Implications of Internships on Early Career Outcomes", National Association for Colleges and Employers, 2017. [Online]. Available:

www.naceweb.org/job-market/internships/the-positive-implications-of-internships-on-early-care er-outcomes/.

[4] College of Engineering and Applied Science, Senior survey data, Boulder, CO: University of Colorado Boulder, 2015-2018.

[5] K. McConnell, J. Steinbrenner and D. Knight, "Push and Pull: Integrating Industry Across the Student Experience", in ASEE Annual Conference \& Exposition, Tampa, FL, 2019.

[6] Office of Data Analytics, Fall enrollment summary by major, Boulder, CO: University of Colorado Boulder, 2018.

[7] "Underrepresented Minorities in STEM", National Action Council for Minorities in Engineering [Online]. Available: www.nacme.org/underrepresented-minorities.

[8] T. Both and D. Baggereor, "Design Thinking Bootcamp Bootleg", Stanford d.school. [Online]. Available: dschool.stanford.edu/resources/the-bootcamp-bootleg.

[9] R. Dam and T. Siang, "Stage 2 in the Design Thinking Process: Define the Problem and Interpret the Results", Interaction Design Foundation. [Online]. Available: www.interaction-design.org/literature/article/stage-2-in-the-design-thinking-process-define-the-p roblem-and-interpret-the-results.

[10] M. Ovando, "Constructive Feedback", International Journal of Educational Management, vol. 8, no. 6, pp. 19-22, 1994. 
[11] A. Bandura, "Self-Efficacy", in Encyclopedia of Human Behavior, 4th ed., V. Ramachaudran, Ed. New York, NY: Academic Press, 1994, pp. 71-81.

[12] S. Dalton (2012). The 2-Hour Job Search (1st ed.). New York, NY: Ten Speed Press.

[13] S. Iyengar and M. Lepper, "When choice is demotivating: Can one desire too much of a good thing?", Journal of Personality and Social Psychology, vol. 79, no. 6, pp. 995-1006, 2000. 